Proc. Indian Acad. Sci. (Earth Planet. Sci.), Vol. 97, No. 2, December 1988, pp. 149-157.

(C) Printed in India.

\title{
Satellite-tracked drifting buoy observations in the south equatorial current in the Indian Ocean
}

\author{
S R SHETYE and G S MICHAEL \\ National Institute of Oceanography, Dona Paula 403004, India
}

MS received 30 December 1987; revised 5 July 1988

\begin{abstract}
Three satellite-tracked drifting buoys released in the south equatorial current in the Indian Ocean followed the path of the current moving westward approximately zonally in the vicinity of $10 \mathrm{~S}$ latitude. On nearing the east coast of Africa two buoys moved north and the third moved south. Over the open sea regime the buoys moved with a speed of approximately $30 \mathrm{~cm} / \mathrm{s}$ at an angle of about $35^{\circ}$ to the left of the wind. The overall tendencies seen in the buoy drift are similar to those observed elsewhere in the world oceans.
\end{abstract}

Keywords. Drifting buoys; south equatorial current; Indian Ocean; surface drift; mixed layer.

\section{Introduction}

In April 1983 three satellite-tracked drifting buoys were released at about $77 \mathrm{E}$ and 10-15 S in the Indian Ocean by the National Institute of Oceanography, Goa, using the vessels MV Farnella and MV Skandi Surveyor. During their lifetime the buoys crossed a zonal band stretching from about $80 \mathrm{E}$ to the east coast of Africa, and from $5 \mathrm{~S}$ to $15 \mathrm{~S}$. The south equatorial current flows in this region.

The drifting buoys used in this study were TOD's manufactured by the Polar Research Laboratory, California, USA. The ARGOS System, France, was used to track the buoys and to collect data recorded by the onboard sensors. On an average about six fixes and data transmissions were obtained per day. The following sensors were onboard: air temperature, atmospheric pressure, wind speed and direction (15 min average, sampled once per sec) and buoy compartment temperature. In this paper we restrict our attention to the observed drift, and to the surface winds measured by using the onboard sensors.

\section{Data}

The wind sensor was located about $90 \mathrm{~cm}$ above the sea surface. During launching, all the three buoys had a $24 \mathrm{~m}$ drogue tethered with its centre about $40 \mathrm{~m}$ below the ocean surface. A drogue sensor sensed whether the drogue stayed attached or not. The design of the buoy is given in figure 1.

The drifters were launched during the second week of April 1983. By November 1983 all the three buoys had reached the east coast of Africa. The drogues came unattached during the early part of the westward journey. The overall performance of the buoys is summarized in table 1 . 


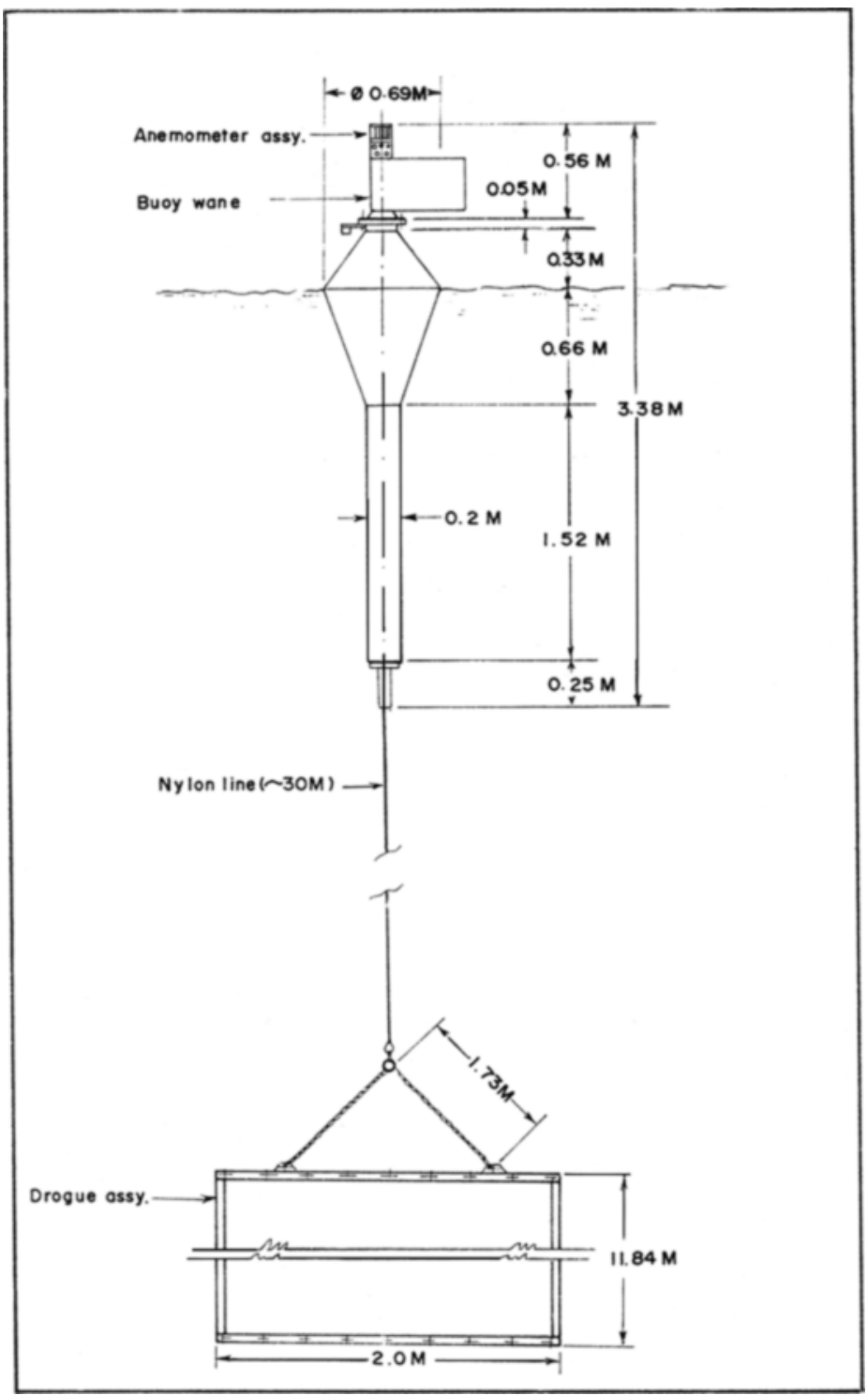

Figure 1. Vertical cross-sectional view of the drifting buoys used in this study.

Figure 2 gives the locations of the buoys with time. As seen from this figure, before entering the coastal current system off Africa, the buoys generally moved westward. The speed of buoys 1730 and 1733 showed little change when the drogues got detached. Buoy 1732 , on the other hand, moved noticeably slower when the drogue was attached, and picked up speed when it got detached. The mean and the standard deviation of the magnitude of the drift of each of the three buoys during each fortnight of their lifetime are summarized in table 2.

Buoy 1732 showed a strong tendency to exhibit damped inertial motions when the drouge was attached. An extreme case of such motions occurred during 17-22 June. 
Table 1. Dates and locations of interest in the performance of the three buoys.

\begin{tabular}{|c|c|c|c|}
\hline & \multicolumn{3}{|c|}{ Buoys } \\
\hline & 1730 & 1732 & 1733 \\
\hline $\begin{array}{c}\text { Deployment } \\
\text { Latitude } \\
\text { Longitude }\end{array}$ & $\begin{array}{c}15 \text { April } 1983 \\
11.907 \mathrm{~S} \\
77.079 \mathrm{E}\end{array}$ & $\begin{array}{c}24 \text { April } 1983 \\
9.812 \mathrm{~S} \\
76.869 \mathrm{E}\end{array}$ & $\begin{array}{c}18 \text { April } 1983 \\
14.473 \mathrm{~S} \\
76.763 \mathrm{E}\end{array}$ \\
\hline $\begin{array}{l}\text { Last report } \\
\text { Latitude } \\
\text { Longitude }\end{array}$ & $\begin{array}{c}8 \text { Oct. } 1983 \\
0.111 \mathrm{~S} \\
42 \cdot 780 \mathrm{E}\end{array}$ & $\begin{array}{c}18 \text { Nov. } 1983 \\
5 \cdot 876 \mathrm{~S} \\
39 \cdot 256 \mathrm{E}\end{array}$ & $\begin{array}{c}28 \text { Sept. } 1983 \\
13 \cdot 148 \mathrm{~S} \\
40.579 \mathrm{E}\end{array}$ \\
\hline Date drogue detached & 28 May 1983 & 1 August 1983 & 10 June 1983 \\
\hline $\begin{array}{l}\text { Date wind magnitude } \\
\text { Sensor broke down }\end{array}$ & 3 July 1983 & 16 Nov. 1983 & 16 Sept. 1983 \\
\hline
\end{tabular}

Details of the motion during this time are given in figure 3. On 16th June the winds recorded by the buoy were of the order of $10 \mathrm{~m} / \mathrm{s}$, and decreased rapidly later. At $10 \mathrm{~S}$ the inertial period was $69 \mathrm{~h}$. Inertial motions similar to, but weaker than, those exhibited by buoy 1732 were also observed in the other two buoys during 17-22 June.

The wind sensor performed best on buoy 1733. Figure 4 has wind vectors plotted at buoy locations along 1733's path. A striking feature revealed by the figure is the buoy's tendency to move to the left of the wind direction. To explore this feature further we computed the angle between the drift over two consecutive buoy locations and the vector mean of the winds reported at the two locations for many such pairs of locations. Only those values for which the magnitude of the vector mean exceeded $1.7 \mathrm{~m} / \mathrm{s}$, the threshold value of the wind sensor, were used. The results for the period after the drogue was detached are summarized in figure 5 . The mean of the angle between the drift and the wind was found to be $35^{\circ}$ with a standard deviation of $44^{\circ}$. The angle did not show any marked dependence on the wind speed.

\section{Discussion}

Studies on drifting buoys carried out over the past decade in different regions of the world oceans have shown that undrogued buoys in the open ocean regime move at an angle to the right of the wind in the northern hemisphere (see McNally 1981, for example). This angle is close to the angle of $45^{\circ}$ predicted by Ekman's theory for winddriven surface flow in the oceans (Ekman 1905). However, doubts about this explanation arise because the present empirical evidence supports the idea of a slablike mixed layer (Niiler and Kraus 1977) in which the velocity remains unchanged through the depth of the slab. These models predict that the surface velocity will be at an angle of $90^{\circ}$ to the right (left) in the northern (southern) hemisphere, i.e. there will be no downwind component of the surface velocity (McNally and White 1985). Buoys, on the other hand, show a well-defined downwind component. Different explanations have been put forth to account for this component. McNally and White (1985) argued that it is caused by the stress exerted by the wind directly on the buoy (windage). Kirwan et al (1979) explained it by invoking Stokes drift. They also pointed out that large-scale geostrophic flow would tend to make the buoys move downwind. 


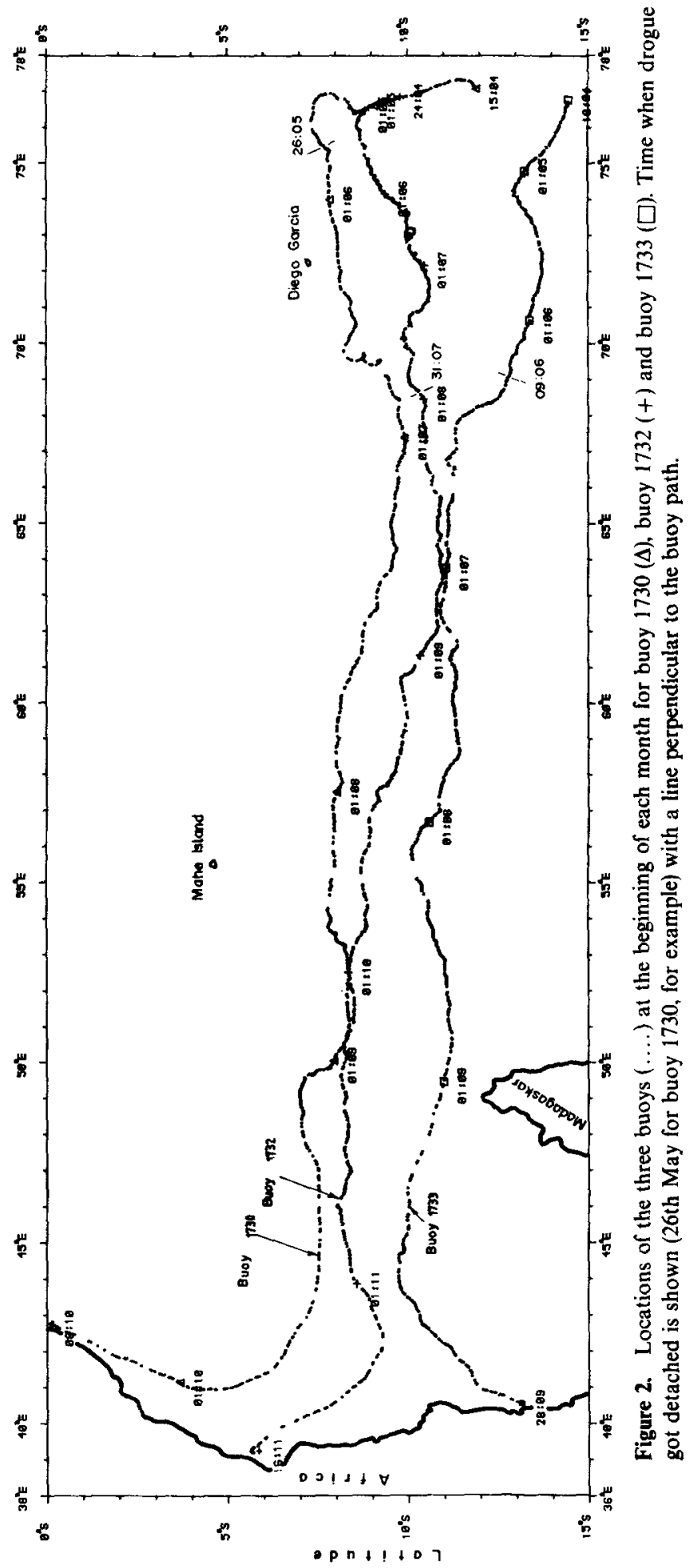


Table 2. Mean and standard deviation (in brackets) of buoy drift in $\mathrm{cm} / \mathrm{s}$.

\begin{tabular}{|c|c|c|c|}
\hline \multirow[b]{2}{*}{ Period } & \multicolumn{3}{|c|}{ Buoys } \\
\hline & 1730 & 1732 & 1733 \\
\hline 16-30 April & $26 \cdot 2(8.8)$ & $20 \cdot 6(10 \cdot 3)$ & $23.6(7.8)$ \\
\hline 1-15 May & $13.4(8.8)$ & $14.7(9.5)$ & $13 \cdot 1(7 \cdot 1)$ \\
\hline 16-31 May & $29 \cdot 7(11 \cdot 6)$ & $12 \cdot 7(7 \cdot 3)$ & $26 \cdot 0(10 \cdot 5)$ \\
\hline 1-15 June & $35.5(15.9)$ & $14 \cdot 3(8 \cdot 2)$ & $33.4(12 \cdot 7)$ \\
\hline 16-30 June & $38 \cdot 0(17 \cdot 1)$ & $22 \cdot 4(11.8)$ & $39 \cdot 0(17.9)$ \\
\hline 1-15 July & $35 \cdot 3(12 \cdot 5)$ & $18 \cdot 3(9 \cdot 0)$ & $33 \cdot 2(20 \cdot 4)$ \\
\hline $16-31$ July & $51 \cdot 6(17 \cdot 4)$ & $25 \cdot 2(11 \cdot 6)$ & $33 \cdot 3(16 \cdot 1)$ \\
\hline 1-15 August & $35 \cdot 3(19 \cdot 7)$ & $32 \cdot 3(12 \cdot 1)$ & $28.5(14.6)$ \\
\hline 16-31 August & $33 \cdot 2(15 \cdot 9)$ & $31.6(12.7)$ & $36 \cdot 1(19 \cdot 4)$ \\
\hline 1-15 September & $39.5(22.0)$ & $39 \cdot 4(19 \cdot 3)$ & $55 \cdot 7(37 \cdot 6)$ \\
\hline 16-30 September & $67 \cdot 1(13 \cdot 3)$ & $44.9(18.5)$ & $45 \cdot 8(18 \cdot 3)$ \\
\hline 1-15 October & $73.5(35.2)$ & $38 \cdot 3(15 \cdot 3)$ & \\
\hline 16-31 October & & $38 \cdot 1(14 \cdot 8)$ & \\
\hline 1-15 November & & $59 \cdot 8(21.0)$ & \\
\hline
\end{tabular}

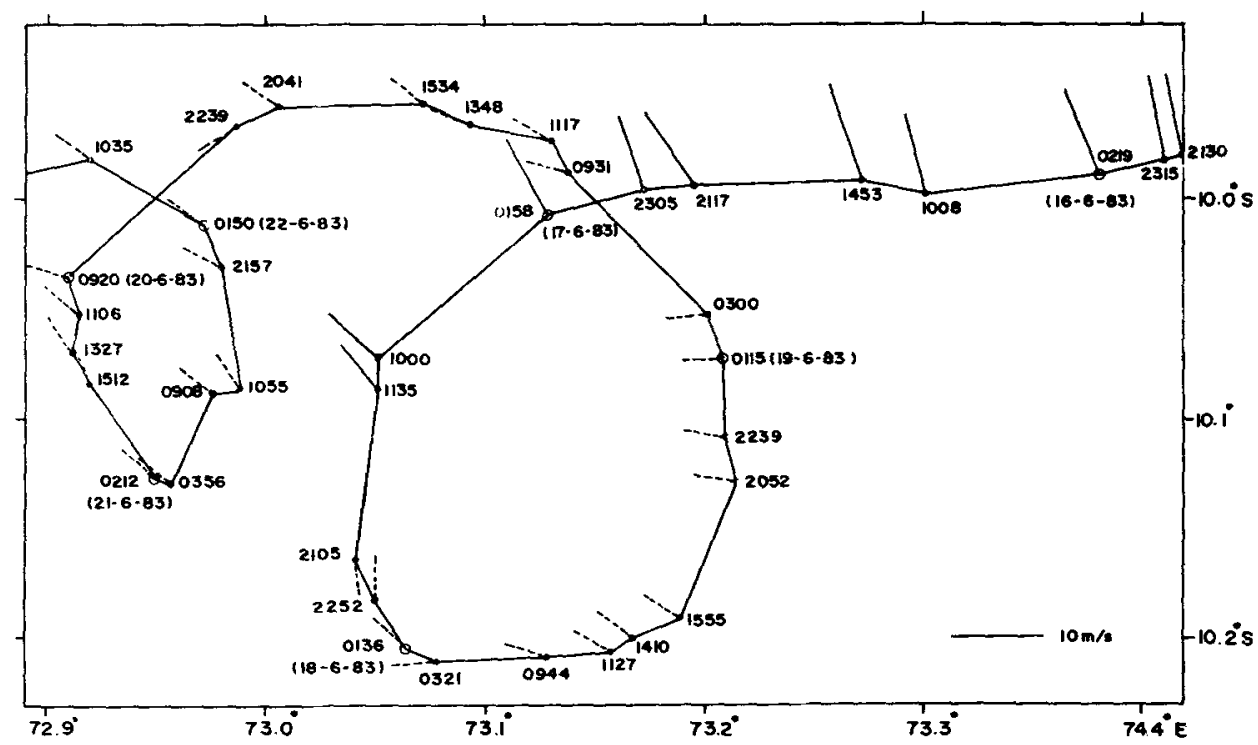

Figure 3. Locations of buoy 1732 during 16-22 June are shown with dots. Times (GMT) at these locations are also shown. Wind sticks start from the location of the buoy and point in the direction of the winds. Wind sticks are drawn as dashed line where magnitude of the winds is less than the threshold value of $5 \mathrm{~m} / \mathrm{s}$. The stick in the lower right hand corner corresponds to $10 \mathrm{~m} / \mathrm{s}$. 


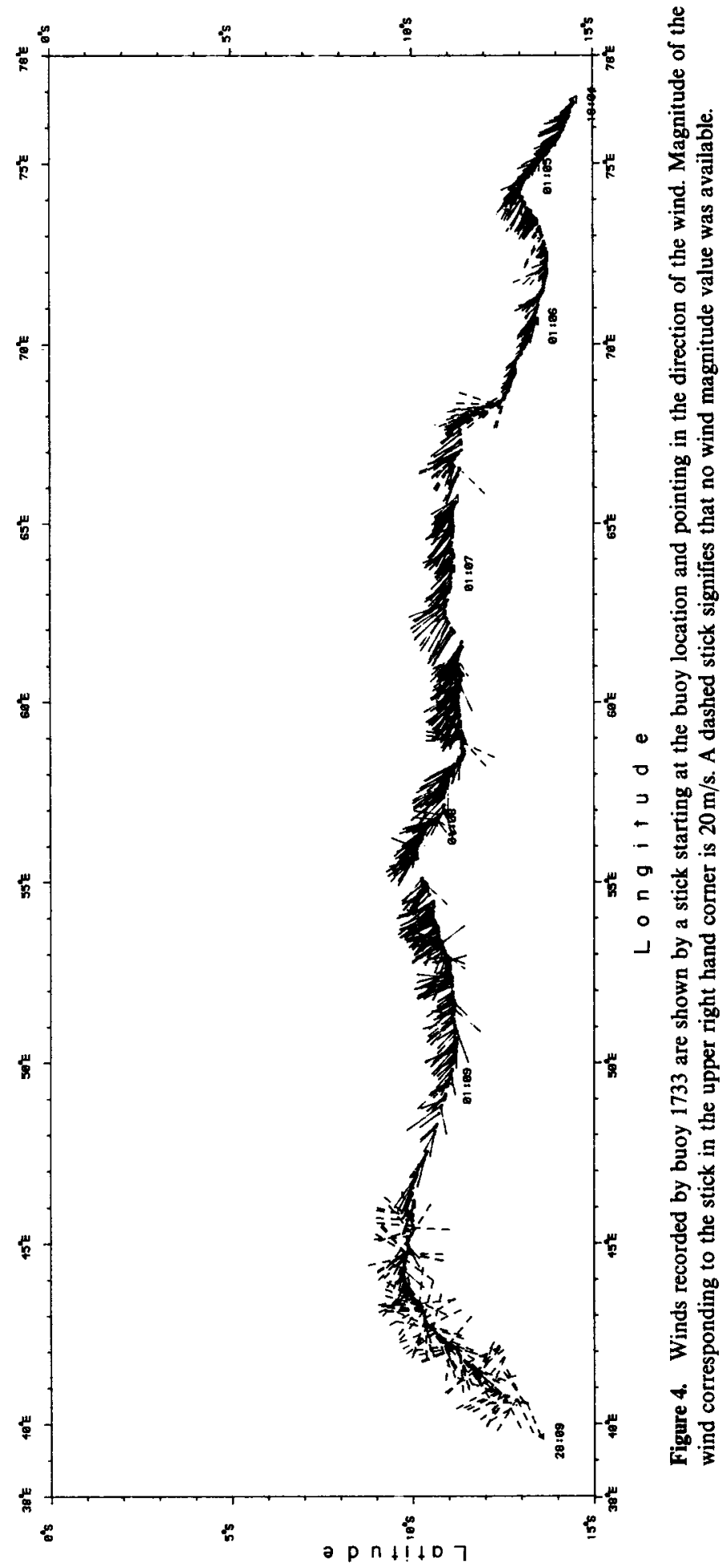




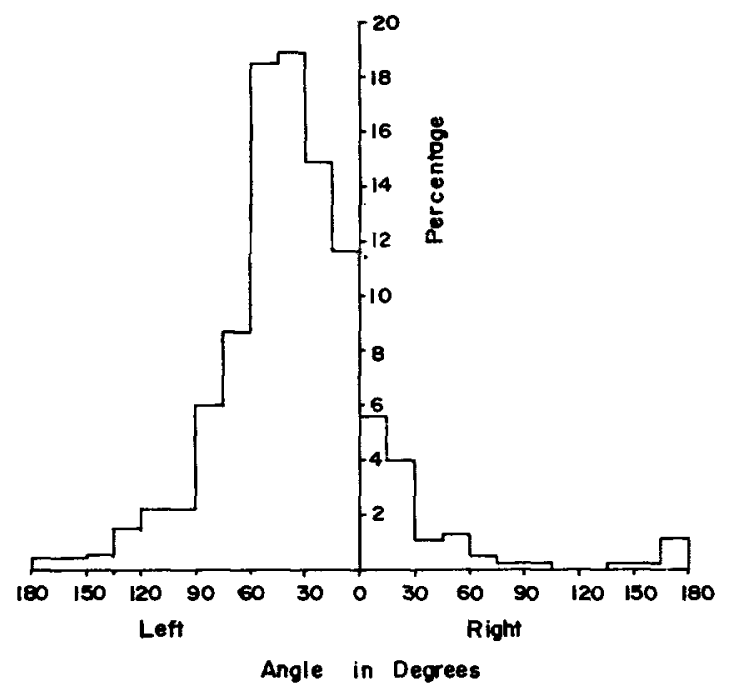

Figure 5. Histogram (from 551 observations) of angles between drift and winds for buoy 1733 after the drogue was detached.

The observed angle between the winds and buoy drift can also be explained by taking into account the friction at the bottom of the mixed layer. In slab mixed layer models the depth $h$ of the mixed layer and surface temperature can be computed using air-sea fluxes of heat and momentum. The velocity can then be computed (see eqn (4.2) of Davies etal (1981)) from the following equations:

$$
\begin{aligned}
& \frac{\partial u}{\partial t}=f v+\frac{1}{\rho h}\left(\tau_{0}^{x}-\tau_{b}^{x}\right)-\frac{1}{h}(u-\tilde{u}) \frac{\partial h}{\partial t} \\
& \frac{\partial v}{\partial t}=-f u+\frac{1}{\rho h}\left(\tau_{0}^{y}-\tau_{b}^{y}\right)-\frac{1}{h}(v-\tilde{v}) \frac{\partial h}{\partial t} .
\end{aligned}
$$

Here $u$ and $v$ are respectively the eastward and northward velocity components in the slab. $f$ is the Coriolis parameter, $\rho$ the density, $\left(\tau_{0}^{x}, \tau_{0}^{y}\right)$ the wind stress, $\left(\tau_{b}^{x}, \tau_{b}^{y}\right)$ the stress at interface between the mixed layer and the underlying ocean, $(\tilde{u}, \tilde{v})$ the velocity just below the slab, and $t$ the time.

If the time scale of interest is much longer than the inertial period, as is generally the case with drifting buoy data, the terms on the left-hand side of ( $1 \mathrm{a}$ ) and (1b) can be safely ignored. The same argument can be used to ignore the last terms on the right-hand side. We now assume that the bottom stress terms can be written as

$$
\tau_{b}^{x}=K_{1} u, \quad \tau_{b}^{y}=K_{1} v,
$$

where $K_{1}$ is a constant. The solution to the velocity field can then be given by

$$
\begin{aligned}
& \left(u^{2}+v^{2}\right)^{1 / 2}=\frac{\tau_{0}}{\left[(\rho f h)^{2}+K_{1}^{2}\right]^{1 / 2}}, \\
& \theta=-\tan ^{-1}\left(\frac{\rho f h}{K_{1}}\right)
\end{aligned}
$$


where $\theta$ is the angle subtended by the drift with the wind vector and $\tau_{0}$ is the magnitude of the wind stress. $U=\left[u^{2}+v^{2}\right]^{1 / 2}$ is the magnitude of the surface current. Equation (3) implies that in the northern (southern) hemisphere the drift angle $\theta$ will be negative (positive), i.e. clockwise (counter clockwise) with respect to the wind vector. It further implies that the magnitude of the angle will increase with latitude and with depth of the mixed layer. At the equator the angle vanishes.

On the whole, the existence of the downwind component can be explained by invoking one or more of the following influences: windage, Stokes drift, influence of interior geostrophic flow and friction at the bottom of the mixed layer. It is not possible at present to determine the relative magnitudes of these effects. Complicating the issue further are the recent data presented by Richman et al (1987) showing the presence of current shear in the uppermost $15 \mathrm{~m}$ of the water column during six days of observation off the west coast of North America. It is not known how common is the occurrence of such shears.

The geostrophic interior flow in the region crossed by the three buoys discussed here is dominated by the south equatorial current (SEC) which is a part of the southern hemispheric subtropical anticyclonic gyre (Wyrtki 1973). As seen in figure 6, a characteristic feature of this gyre is the long high-pressure ridge that extends from the Agulhas current system at the western edge to the Timor Sea on the east. The westward SEC is located north of the ridge. The current, on reaching the latitude of about $50 \mathrm{E}$, near the northern tip of Madagascar, bifurcates, one branch flowing southward along the east coast of Madagascar and the other continues westward. The latter, on approaching the coast of Africa bifurcates again, one branch flowing northward and the other southward into the Agulhas current system. It appears that the separation of the buoys, on reaching the coast of Africa, one moving south and the other two moving north occurred in response to the bifurcation of the SEC near the coast. As seen from table 2 the buoys picked up speed on moving into the coastal region.

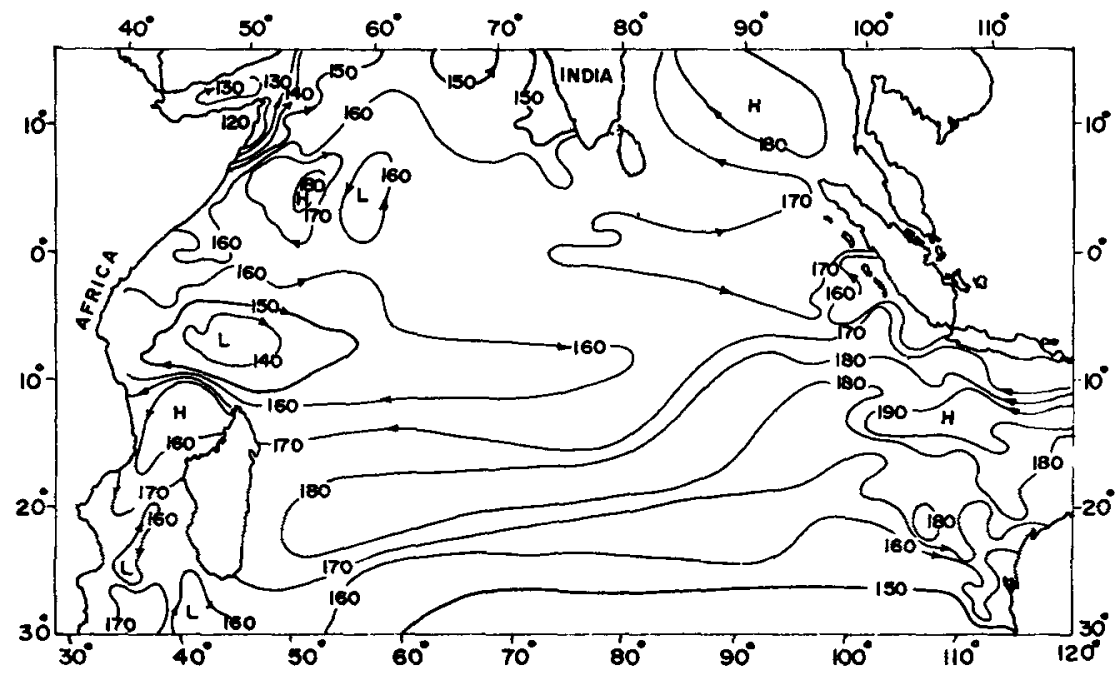

Figure 6. Dynamic topography (dynamic cm) of the sea surface relative to 1000 decibars during July-August (figure taken from Wyrtki (1973)). 
Available data suggest that the mixed-layer depth around $75 \mathrm{E}$ and $10 \mathrm{~S}$ during May-June is in the range of 20 to $60 \mathrm{~m}$ (Wyrtki 1971). It is possible that in the region crossed by buoy 1732 during June--July the mixed layer was less than $40 \mathrm{~m}$, the depth of the buoy drogue. In such a case the buoy would move much slower with the lower velocities below the mixed layer.

\section{Conclusions}

In summary, the three buoys generally followed the path of the SEC moving westward approximately zonally in the vicinity of $10 \mathrm{~S}$. On reaching the west coast of Africa the buoys separated, two moving north and the third moving south apparently in response to the bifurcation of the SEC. Over the open ocean regime the buoys moved at an angle of about $35^{\circ}$ to the left of the winds, with a speed of about $30 \mathrm{~cm} / \mathrm{s}$. Though it is not possible at present to determine the precise dynamical reasons behind the movement exhibited by the buoys, the overall tendencies shown by them are similar to those observed in other parts of the world oceans.

\section{Acknowledgements}

This research has been supported by grants from the Department of Ocean Development, Government of India, New Delhi. Programming support during the course of the data analyses was provided by the Ocean Engineering and Pipeline Section and the Computer Section of MECON, Ranchi.

\section{References}

Davies R E, de Szoeke R and Niiler P 1981 Variability in the upper ocean during MILE. Part II: Modelling and mixed layer response; Deep-Sea Res. A28 1453-1475

Ekman V W 1905 On the influence of earth's rotation on ocean currents; Ark. Mat. Astron. Fys. 2 1-53

Kirwan A D Jr., McNally G, Pazan S and Wert R 1979 Analysis of surface current response to winds; $J$. Phys. Oceanogr. $9401-412$

McNally G J 1981 Satellite-tracked drift buoy observations of the near-surface flow in the eastern mid-latitude north Pacific; J. Geophys. Res. 86 8022-8030

McNally $G J$ and White W $B$ I985 Wind-driven flow in the mixed layer observed by drifting buoys during autumn-winter in the mid-latitude north Pacific; J. Phys. Oceanogr. 15 684-694

Niiler P P and Kraus E B 1977 One-dimensional models of the upper ocean. In Modelling and prediction of the upper layers of the acean (ed.) E B Kraus (Oxford: Pergamon Press)

Richman J G, de Szoeke R A and Davis R E 1987 Measurement of near-surface shear in the ocean; $J$. Geophys. Res. 92 2857-2858

Wyrtki K 1971 Oceanographic atlas of the international Indian Ocean expedition (Washington DC: US Government Printing Office)

Wyrtki K 1973 Physical oceanography of the Indian Ocean. In Biology of the Indian Ocean (ed.) B Zietzschel (New York: Springer-Verlag) pp. 18-36 